\title{
Comparación de los hallazgos clínicos y de supervivencia entre pacientes VIH positivos y VIH negativos con criptococosis meníngea en un hospital de tercer nivel
}

\author{
Comparison of Clinical Findings and Survival \\ Among HIV Positive Patients and HIV-Negative with \\ Cryptococcal Meningitis in a Tertiary Care Hospital
}

\author{
Jairo Lizarazo, Óscar Chaves, Yeni Peña • Cúcuta (Colombia). Patricia Escandón, \\ Clara Inés Agudelo, Elizabeth Castañeda • Bogotá, D.C. (Colombia)
}

\section{Resumen}

Introducción: en Colombia ha sido documentada la incidencia incrementada de la criptococosis, al igual que una alta prevalencia de criptococosis por $C$. gattii en Cúcuta.

Objetivo: hacer un análisis de los pacientes con criptococosis meníngea atendidos en un hospital de tercer nivel de atención en Cúcuta, Colombia, estableciendo diferencias según su estado de portador del VIH.

Materiales y métodos: se realizó un estudio retrospectivo de revisión de historias clínicas en donde se evaluaron las características clínicas y los resultados de los pacientes con diagnóstico de criptococosis meníngea durante el periodo de estudio de 15 años (1996-2010).

Resultados: se analizaron 90 casos, 63 (70\%) VIH positivos y 27 (30\%) VIH negativos. La mayoría de los pacientes VIH positivos fueron adultos jóvenes ( $81 \%$ vs $25.9 \%$ de los pacientes VIH negativos, $p=<0.001)$. Hubo una alta prevalencia de niños entre los pacientes VIH negativos (29.6 vs $0 \%, p=$ $<0.001$ ). La relación hombre: mujer fue mayor en los pacientes VIH positivos (3.8 vs 2.4; $p=0.001$ ). No se encontró factor de riesgo en $88.9 \%$ de los pacientes VIH negativos. Entre los pacientes VIH positivos la mayoría $(76.2 \%)$ no recibía terapia antirretroviral, muy pocos $(7.9 \%)$ tomaban profilaxis con fluconazol y $68.8 \%$ tenía $<100$ células CD4+. La hipertensión intracraneana sin hidrocefalia $(83.3$ vs $48.0 \%, p=0.009)$, los cambios visuales ( 48.1 vs $20.6 \%, p=0.02)$ y la criptococosis extraneural (22.2 vs $6.4 \%, p=0.06$ ) fueron más frecuentes en los pacientes VIH negativos. Los pacientes VIH negativos tuvieron mayor número de leucocitos $(124.2 / \mathrm{ml}$ vs $43.0 / \mathrm{ml}, \mathrm{p}=0.002)$ y de proteínas $(113.6$ vs $89.7 \mathrm{mg} / \mathrm{dL}, p<0.001)$ en el LCR. C. neoformans var. grubii se aisló con mayor frecuencia en los pacientes VIH positivos (100 vs $40 \%, p<0.001)$ y $C$. gattii predominó en los VIH negativos (60\% vs $0 \%, p<0.001)$. La TAC de cráneo fue más frecuentemente anormal en los pacientes VIH positivos (73.3 vs $22.7 \%, p<0.001$ ). La mayoría de los pacientes en ambos grupos recibieron anfotericina $\mathrm{B}$ como terapia primaria (96.8\% de los VIH positivos vs $85.2 \%$ de los VIH negativos). La letalidad hospitalaria fue mayor en los pacientes VIH positivos (49.2 vs $16.0 \%, p=0.004)$. Fueron factores de mal pronóstico: la infección por el VIH, la alteración del estado de conciencia, la falta de terapia antirretroviral en los pacientes VIH positivos, las convulsiones y la baja celularidad en el LCR. Las secuelas neurológicas fueron frecuentes en ambos grupos de pacientes (40.6\% vs 32.0\%) sin existir diferencia significativa. La probabilidad de supervivencia fue significativamente mayor en los pacientes VIH negativos ( $82 \%$ vs $46 \%, p=0.0066$ ).

Conclusiones: la criptococosis tiene una alta morbilidad y mortalidad, especialmente en los pacientes VIH positivos. Es muy alta la prevalencia de criptococosis por $C$. gattii y de niños en la población VIH negativa. (Acta Med Colomb 2012; 37: 49-61).
Dres. Jairo Lizarazo, Óscar Chaves y Yeni Peña: Hospital Universitario Erasmo Meoz, Cúcuta; Dras. Patricia Escandón, Clara Inés Agudelo y Elizabeth Castañeda: Instituto Nacional de Salud, Bogotá, D.C. Colombia Correspondencia: Dr. Jairo Lizarazo, Cúcuta, Norte de Santander (Colombia). E-mail: jflizar@gmail.com

Fuentes de financiación. Hospital Universitario Erasmo Meoz de Cúcuta y el Instituto Nacional de Salud, Bogotá D.C., Colombia. Conflicto de interés. Los autores declaramos no tener conflicto de interés alguno. Recibido: 13/XII/2011 Aceptado: 16/V/2012 
Palabras clave: Criptococosis meníngea, Cryptococcus neoformans, Cryptococcus gattii, síndrome de inmunodeficiencia adquirida, meningitis, letalidad, supervivencia.

\section{Abstract}

Introduction: an increased incidence of cryptococcosis has been documented in Colombia, as well as a high prevalence of Cryptococcus gattii in Cucuta.

Objective: to analyze patients with cryptococcal meningitis treated at a tertiary care hospital in Cucuta, Colombia, according to the HIV carrier status.

Materials and methods: we performed a retrospective review of medical records in which we evaluated the clinical characteristics and outcomes of patients diagnosed with cryptococcal meningitis during the study period of 15 years (1996-2010).

Results: we analyzed 90 cases, $63(70 \%)$ HIV positive and 27 (30\%) HIV negative. Most HIVpositive patients were young adults $(81.0 \%$ versus $25.9 \%$ of HIV negative patients, $\mathrm{p}=<0.001)$. There was a high prevalence of children among HIV-negative patients $(29.6$ versus $0 \%, \mathrm{p}=<0.001)$. The male: female ratio was higher in HIV positive patients (3.8 versus $2.4, \mathrm{p}=0.001$ ). No risk factor was found in $88.9 \%$ of HIV negative patients. Among the HIV-positive patients, mos of them $(76.2 \%)$ were not receiving antiretroviral therapy, very few $(7.9 \%)$ were taking prophylaxis with fluconazole and $68.8 \%$ had $<100 \mathrm{CD} 4+$ cells. Intracranial hypertension without hydrocephalus $(83.3$ versus $48.0 \%, \mathrm{p}$ $=0.009)$, visual changes $(48.1$ versus $20.6 \%, \mathrm{p}=0.02)$ and extraneural cryptococcosis $(22.2$ versus 6 , $4 \%, \mathrm{p}=0.06$ ) were more frequent in HIV-negative patients. HIV-negative patients had higher numbers of leukocytes $(124.2 / \mathrm{ml}$ versus $43.0 / \mathrm{ml}, \mathrm{p}=0.002)$ and protein $(113.6$ versus $89.7 \mathrm{mg} / \mathrm{dL}, \mathrm{p}<0.001)$ in the CSF. C. neoformans var. grubii was isolated more frequently in HIV-positive patients (100 versus $40 \%, \mathrm{p}<0.001)$ and $C$. gattii was predominant in HIV-negative $(60 \%$ versus $0 \%, \mathrm{p}<0.001)$. CT skull was more frequently abnormal in HIV-positive patients $(73.3$ versus $22.7 \%, \mathrm{p}<0.001)$. Most patients in both groups received amphotericin B as primary therapy ( $96.8 \%$ of HIV positive versus $85.2 \%$ of HIV negative). The hospital mortality was higher in HIV positive patients $(49.2$ versus $16.0 \%, \mathrm{p}=0.004$ ). HIV infection, altered state of consciousness, lack of antiretroviral therapy in HIV-positive patients, seizures and low CSF cellularity were factors of poor prognosis. Neurological sequelae were common in both groups of patients ( $40.6 \%$ vs $32.0 \%$ ) without significant difference. The probability of survival was significantly higher in HIV-negative patients $(82 \%$ vs $46 \%, \mathrm{p}=0.0066)$.

Conclusions: cryptococcosis has a high morbidity and mortality, especially in HIV positive patients. The prevalence of Cryptococcus gattii in the HIV negative population and in children is very high. (Acta Med Colomb 2012; 37: 49-61).

Keywords: meningeal cryptococcosis, Cryptococcus neoformans, Cryptococcus gattii, AIDS, meningitis, lethality, survivability.

\section{Introducción}

La criptococosis es una micosis sistémica causada por el complejo de especies patógenas del género Cryptococcus a saber: $C$. neoformans y $C$. gattii. Este hongo es una levadura encapsulada que se puede aislar del ambiente y cuya manifestación clínica más grave es la afectación del sistema nervioso central (SNC) (1). En el mundo, la criptococosis meníngea es muy frecuente, y afecta especialmente a los pacientes infectados por el VIH y a los individuos sometidos a terapia inmunosupresora. Se ha calculado globalmente en casi un millón de casos anuales de criptococosis meníngea en pacientes con SIDA, de ellos el 75\% habitan en el África Subsahariana, con una mortalidad de casi las $2 / 3$ partes de los afectados (2).

En Colombia, el Grupo Colombiano para el Estudio de la Criptococosis ha señalado para este país una incidencia promedio anual de 2.4 casos por millón en la población general y de tres casos por mil en los pacientes VIH positivos (3).

Teniendo en cuenta que $60 \%$ de los casos de criptococosis por C. gattii diagnosticados en Colombia son del departamento Norte de Santander (4) y que su agente etiológico Cryptococcus gattii afecta en más de $90 \%$ de las veces a individuos aparentemente inmunocompetentes (5), se decidió comparar, en forma retrospectiva, las presentaciones clínicas, los datos del laboratorio, los hallazgos de las imágenes diagnósticas y los resultados de las criptococosis meníngeas entre pacientes VIH positivos y VIH negativos admitidos en el Hospital Universitario Erasmo Meoz de Cúcuta, Norte de Santander, durante los años 1996-2010.

\section{Material y métodos}

En forma retrospectiva se revisaron las historias clínicas de los pacientes hospitalizados con diagnóstico de cripto- 
cocosis meníngea durante los años 1996 a 2010. La criptococosis meníngea se definió por la positividad en el líquido cefalorraquídeo (LCR) de al menos una de las siguientes pruebas; exclusión con tinta china, antígeno capsular de Cryptococcus en cualquier dilución o recuperación del hongo en el cultivo.

Para su análisis los pacientes fueron divididos en dos grupos: los VIH positivos y los VIH negativos. Se diseñó un instrumento para la recolección de la información y en una base de datos se registraron la edad, el sexo, los factores de riesgo para la criptococosis, la procedencia de los pacientes, las manifestaciones clínicas iniciales con su tiempo de evolución, los hallazgos del examen neurológico, los resultados de los exámenes del LCR, la descripción de las imágenes diagnósticas, el tratamiento efectuado, la letalidad hospitalaria, las secuelas, las recaídas y la supervivencia a 120 días.

La infección por el VIH fue diagnosticada mediante el método de detección de anticuerpos por la prueba de ELISA y se confirmó mediante la prueba de Western blot. En los pacientes VIH positivos se revisó la información sobre la terapia antirretroviral (TAR), y el número de células T CD4+.

En el LCR se evaluaron la presión de apertura durante la punción lumbar, el número y tipo de leucocitos, las proteínas, la glucosa, la exclusión de la tinta china, la determinación del antígeno capsular mediante la prueba del látex y el cultivo. En algunos casos, también se determinó el antígeno capsular de Cryptococcus en suero. Para cuantificar el antígeno capsular se utilizó el estuche comercial CALAS ${ }^{\circledR}$ (Meridian Bioscience, Inc, USA). Los aislamientos fueron enviados al Instituto Nacional de Salud en Bogotá D.C., en donde se determinó la especie mediante el cultivo en canavanina-glicina-azul de bromotimol (CGB). Al principio, se estableció el serotipo del aislamiento mediante la utilización de antisueros específicos y en los últimos años se investigó el patrón molecular mediante la técnica de PCR huella digital (6).

Se revisaron las imágenes diagnósticas, específicamente las radiografías del tórax, la tomografía axial computadorizada (TAC) de cráneo y la resonancia magnética (RM) de cerebro.

Se precisó el tipo de tratamiento antifúngico utilizado y su duración. Se determinó la terapia realizada para el manejo de la hipertensión intracraneana asociada con la criptococosis meníngea. Igualmente, se investigaron el tipo de cirugías requeridas.

Para el análisis estadístico se utilizó el programa EPI Info versión 3.5.1. Las variables continuas se describieron utilizando promedios y desviaciones estándares y se compararon utilizando la prueba $t$ de Student. Las variables categóricas se compararon mediante la prueba $x^{2}$. Se consideraron significativas las diferencias con una $p<0.05$. Se llevó a cabo un análisis univariado de los factores asociados con letalidad. La supervivencia se describió utilizando el método de Kaplan-Meier.

\section{Resultados}

Durante los 15 años (1996-2010) se diagnosticaron 90 casos de criptococosis meníngea. De éstos, 63 pacientes (70\%) fueron VIH positivos. Las comparaciones de los datos demográficos y de las manifestaciones clínicas de los grupos de pacientes VIH positivos y VIH negativos están consignados en la Tabla 1. Los pacientes VIH positivos fueron más jóvenes y en los VIH negativos hubo una alta proporción (29.6\%) de niños. También, $88.9 \%$ de los pacientes VIH negativos no tenía un factor de riesgo conocido.

Sólo 23.8\% (15/63) de los pacientes con sida estaban recibiendo TAR, 7.9\% (5/63) estaban tomando profilaxis con fluconazol, 68.8\% (22/32) estaban muy inmunosuprimidos (<100 células CD4+) y la criptococosis meníngea definió sida en $84.1 \%$ (53/63).

En los pacientes VIH negativos, sólo tres $(11.1 \%)$ tenía algún otro factor de riesgo (dos artritis reumatoidea y uso de esteroides y un neonato con infección congénita por citomegalovirus). El 84.4\% (76/90) de los pacientes provenía del área metropolitana de Cúcuta y no existió diferencia entre los pacientes VIH positivos $(55 / 63,87.3 \%$ ) y los VIH negativos $(21 / 27,77.7 \%)$ con relación a su procedencia. $\mathrm{La}$ procedencia rural se dio en $13.3 \%$ (12/90) de los pacientes, siendo más frecuente en los pacientes VIH negativos (18.5\%, $5 / 27)$ que en los pacientes con sida $(11.1 \%, 7 / 63)$ pero sin alcanzar significancia estadística.

De las manifestaciones clínicas, fueron significativamente más frecuentes en los pacientes VIH negativos los cambios visuales y la criptococosis extraneural. Si bien es cierto que la hipertensión intracraneana sin hidrocefalia estuvo presente en la mayoría de los pacientes (57.3\%), ésta fue más común en los pacientes VIH negativos $(83.3 \%$ vs $48 \%, p=0.009$ ). Un número significativo de pacientes VIH positivos $(12.7 \%)$ tuvieron un examen neurológico inicial normal, mientras que todos los pacientes VIH negativos presentaron alguna anormalidad en la valoración clínica. El tiempo de evolución de los síntomas fue mayor en los pacientes VIH negativos (44.1 días vs. 19.3 días, $p<0.001$ ) Tabla 1.

Los resultados de las pruebas del laboratorio y los hallazgos imaginológicos se muestran en la Tabla 2. Significativamente, los pacientes VIH positivos tuvieron en el LCR menos células $(43 / \mathrm{mL}$ vs $124 / \mathrm{mL}, p=0.002)$ y un valor de proteínas inferior $(89.7 \mathrm{mg} / \mathrm{dL}$ vs $113.6 \mathrm{mg} / \mathrm{dL}, p<0.001)$. De hecho, $54.2 \%$ de los pacientes con sida tenían $<20$ células/ $\mathrm{mL}$ en el LCR.

No hubo diferencias significativas en el rendimiento de las pruebas confirmatorias de la criptococosis. De 54 aislamientos analizados, $100 \%$ de los recuperados en pacientes con sida correspondió a $C$. neoformans var. grubii mientras que esta variedad sólo correspondió a $40 \%$ de los aislamientos recuperados de pacientes VIH negativos; en $60 \%$ de éstos se identificó $C$. gattii.

El patrón molecular más frecuentemente encontrado fue el VNI (76\%), entre los pacientes VIH positivos alcanzó 
Tabla 1. Hallazgos demográficos y clínicos en pacientes VIH positivos y VIH negativos con criptococosis meníngea.

\begin{tabular}{|c|c|c|c|c|}
\hline \multirow{2}{*}{ Hallazgos demográficos y clínicos } & \multicolumn{2}{|c|}{ Estado del VIH } & \multirow{2}{*}{$\begin{array}{l}\text { Total } \\
\mathbf{n}=90\end{array}$} & \multirow[t]{2}{*}{$p$} \\
\hline & $\begin{array}{c}\text { Positivo } \\
\mathrm{n}=63(70 \%)\end{array}$ & $\begin{array}{c}\text { Negativo } \\
\mathrm{n}=27(30 \%)\end{array}$ & & \\
\hline \multicolumn{5}{|l|}{ Edad } \\
\hline $\begin{array}{l}\text { Edad en años } \pm \text { DE } \\
\text { (rango) }\end{array}$ & $\begin{array}{c}34.0 \pm 9.2 \\
(24-64)\end{array}$ & $\begin{array}{c}33.6 \pm 19.4 \\
(0-65)\end{array}$ & $\begin{array}{c}33.9 \pm 13.0 \\
(0-65)\end{array}$ & \\
\hline 20-39 años n (\%) & $51(81.0)$ & $7(25.9)$ & $58(65.9)$ & $<0.001$ \\
\hline $40-65$ años n (\%) & $12(19.0)$ & $12(44.4)$ & $24(26.7)$ & \\
\hline Niños edad $<16$ años $n(\%)$ & $0(0.0)$ & $8(29.6)$ & $8(9.1)$ & $<0.001$ \\
\hline \multicolumn{5}{|l|}{ Sexo } \\
\hline Masculino n (\%) & $50(79.4)$ & $19(70.4)$ & $69(76.7)$ & \\
\hline Relación M:F & 3.8 & 2.4 & 3.3 & 0.001 \\
\hline Procedencia & \multicolumn{4}{|c|}{$\mathrm{n}(\%)$} \\
\hline Rural & $7(11.1)$ & $5(18.5)$ & $12(13.3)$ & \\
\hline Urbana & $56(88.9)$ & $22(81.5)$ & $78(86.7)$ & \\
\hline \multicolumn{5}{|l|}{ Manifestaciones clínicas } \\
\hline $\begin{array}{l}\text { Evolución de los síntomas (días) } \pm D E \\
\text { Rango } \\
\text { Mediana }\end{array}$ & $\begin{array}{c}19.3 \pm 26.9 \\
1-120) \\
10\end{array}$ & $\begin{array}{l}44.1 \pm 47.7 \\
(9-240) \\
30\end{array}$ & $\begin{array}{c}26.8 \pm 36.0 \\
(1-240) \\
15\end{array}$ & $<0.001$ \\
\hline \multicolumn{5}{|c|}{ n (\%) } \\
\hline Cefalea & $55(87.3)$ & $26(96.3)$ & $81(90.0)$ & \\
\hline Náuseas/vómitos & $38(60.3)$ & $19(70.4)$ & $57(63.3)$ & \\
\hline Hipertensión intracraneana sin hidrocefalia ${ }^{1}$ & $24(48.0)$ & $15(83.3)$ & $39(57.3)$ & 0.009 \\
\hline Fiebre & $35(55.6)$ & $13(48.1)$ & $48(53.3)$ & \\
\hline Alteración de conciencia & $35(55.6)$ & $11(40.7)$ & $46(51.1)$ & \\
\hline Cambios mentales & $29(46.0)$ & $9(33.3)$ & $38(42.2)$ & \\
\hline Signos meníngeos & $22(34.9)$ & $12(48.0)$ & $34(37.8)$ & \\
\hline Cambios visuales & $13(20.6)$ & $13(48.1)$ & $26(28.9)$ & 0.02 \\
\hline Focalización neurológica & $18(28.6)$ & $6(22.2)$ & $24(26.7)$ & \\
\hline Convulsiones & $17(27.0)$ & $4(14.8)$ & $21(23.3)$ & 0.3 \\
\hline Criptococosis extraneural & $4(6.4)$ & $6(22.2)$ & $10(11.1)$ & 0.06 \\
\hline Tos & $5(7.9)$ & $3(11.1)$ & $8(8.9)$ & \\
\hline Hidrocefalia & $1(1.6)$ & $4(14.8)$ & $5(5.6)$ & 0.01 \\
\hline Examen neurológico normal & $8(12,7)$ & $0(0)$ & $8(8,9)$ & 0.05 \\
\hline
\end{tabular}

$97.1 \%$ y entre los VIH negativos $40 \%$. En los pacientes VIH negativos se identificaron todos los patrones moleculares del C. gattii, (VGI a VGIV) con predominio del VGII, el cual se identificó en $30 \%$ (Tabla 2).

En un criptococoma pulmonar de una paciente VIH negativa se cultivó C. neoformans var. grubii (Figura 1). Entre los ocho niños, en cuatro se encontró $C$. neoformans var. grubii, en uno $C$. gattii serotipo B y en tres no se determinó la especie.

Se realizó radiografía del tórax en 64 casos $(71.1 \%)$. En más de la tercera parte de los pacientes de ambos grupos el estudio fue anormal. Estas anormalidades fueron: infiltrados pulmonares (14 casos, ocho VIH positivos), masa pulmonar o criptococomas (tres casos, todos VIH negativos) (Figura 1), condensación pulmonar (dos casos, uno VIH positivo), derrame pleural (dos casos, ambos VIH positivos), nódulo pulmonar (dos casos, ambos VIH positivos), fibrosis pulmonar (un caso, VIH negativo) y caverna ( 1 caso, VIH positivo). Algunos pacientes presentaron más de una anormalidad.

En cuanto a la TAC de cráneo, ésta fue realizada en 84 pacientes $(93.3 \%)$ y en $83(98.8 \%)$, el estudio se llevó a cabo sin la administración del medio de contraste; hubo más anormalidades en los pacientes con sida $(73.3 \%$ vs. 
Tabla 2. Hallazgos del laboratorio y de las imágenes diagnósticas en pacientes VIH positivos y VIH negativos con criptococosis meníngea.

\begin{tabular}{|c|c|c|c|c|}
\hline \multirow[t]{2}{*}{ Resultados } & \multicolumn{2}{|c|}{ Estado del VIH } & \multirow[t]{2}{*}{ Total } & \multirow{2}{*}{$\mathbf{p}$} \\
\hline & $\begin{array}{c}\text { Positivo } \\
n=63(70 \%)\end{array}$ & $\begin{array}{c}\text { Negativo } \\
\mathbf{n}=\mathbf{2 7}(\mathbf{3 0 \%})\end{array}$ & & \\
\hline \multicolumn{5}{|l|}{ Estudio citoquímico } \\
\hline Mediana & $\begin{array}{c}43.0 \pm 79.2 \\
(0-384) \\
14\end{array}$ & $\begin{array}{c}124.2 \pm 172.2 \\
(4-720) \\
45\end{array}$ & $\begin{array}{c}65.8 \pm 117.8 \\
(0-720) \\
23\end{array}$ & 0.002 \\
\hline$<20$ células $/ \mathrm{mL}$ & $32 / 59(54.2)$ & $6 / 23(26.0)$ & $38 / 82(46.3))$ & 0.02 \\
\hline Predominio linfocítico ${ }^{2} \mathrm{n} / \mathrm{T}(\%)$ & $48 / 59(81.4)$ & $15 / 23(65.2)$ & $63 / 82(76.8)$ & 0.12 \\
\hline Glucorraquia $(\mathrm{mg} / \mathrm{dL})^{3}$ & $29.1 \pm 16.7$ & $27.3 \pm 20.9$ & $28.6 \pm 17.8$ & \\
\hline Mediana & 29 & 27 & 28.5 & \\
\hline Glucorraquia <50 mg/dL n/T (\%) & $54 / 61(88.5)$ & 19/23 (82.6) & $73 / 84(86.9)$ & \\
\hline Proteinorraquia $(\mathrm{mg} / \mathrm{dL})^{4}$ & $89.7 \pm 95.5$ & $113.6 \pm 104.6$ & $96.0 \pm 97.9$ & $<0.001$ \\
\hline Mediana & 58.8 & 74.2 & 63.5 & \\
\hline Proteinorraquia $>45 \mathrm{mg} / \mathrm{dL} \mathrm{n} / \mathrm{T}(\%)$ & $40 / 61(65.6)$ & $19 / 22(86.4)$ & $59 / 83(71.1)$ & 0.05 \\
\hline \multicolumn{3}{|l|}{ Estudio microbiológico } & \multicolumn{2}{|c|}{$\mathrm{n} / \mathrm{T}(\%)$} \\
\hline Tinta china positiva & $53 / 61(86.9)$ & $24 / 26(92.3)$ & $77 / 87(88.2)$ & NS \\
\hline Látex en LCR reactivo & $30 / 33(90.9)$ & 9/9 (100.0) & $39 / 42(92.9)$ & NS \\
\hline Látex en suero reactivo & $25 / 28(89.3)$ & $7 / 9(77.8)$ & $32 / 37(86.5)$ & NS \\
\hline Cultivo positivo & $47 / 48(97.9)$ & $23 / 23(100.0)$ & $70 / 71(98.6)$ & \\
\hline C. neoformans var grubii & $34 / 34(100.0)$ & $8 / 20(40.0)$ & $42 / 54(77.8)$ & $<0.001$ \\
\hline \multicolumn{5}{|l|}{ Patrón molecular } \\
\hline VNI & $33 / 34(97.1)$ & $8 / 20(40)$ & $41 / 54(76)$ & \\
\hline VNII & $1 / 34(2.9)$ & & $1 / 54(1.8)$ & \\
\hline C. gattii & $0 / 34(0.0)$ & $12 / 20(60.0)$ & $12 / 54(22.2)$ & $<0.001$ \\
\hline C. gatti serotipo B & & $8 / 10(80.0)$ & & \\
\hline C. gatti serotipo C & & $2 / 10(20.0)$ & & \\
\hline Sin serotipo & & 2 & & \\
\hline \multicolumn{5}{|l|}{ Patrón molecular } \\
\hline VGI & & $1 / 20(5)$ & $1 / 54(1.8)$ & \\
\hline VGII & & $6 / 20(30)$ & $6 / 54(11.2)$ & \\
\hline VGIII & & $4 / 20(20)$ & $4 / 54(7.4)$ & \\
\hline VGIV & & $1 / 20(5)$ & $1 / 54(1.8)$ & \\
\hline \multicolumn{5}{|l|}{ Radiografía del tórax n/T (\%) } \\
\hline Normal & $28 / 41(6.3)$ & $12 / 23(52.2)$ & $40 / 64(62.5)$ & NS \\
\hline Anormal & $13 / 41(31.7)$ & $11 / 23(47.8)$ & $24 / 64(37.5)$ & 0.20 \\
\hline \multicolumn{5}{|l|}{ TAC de cráneo n/T (\%) } \\
\hline Normal & $16 / 60(26.7)$ & $16 / 24(66.6)$ & $32 / 84(38.1)$ & $<0.001$ \\
\hline Anormal & $44 / 60(73.3)$ & $5 / 24(22.7)$ & $52 / 84(61.9)$ & $<0.001$ \\
\hline Atrofia cerebral & $31 / 60(51.7)$ & $1 / 24(4.2)$ & $32 / 84(38.1)$ & $<0.001$ \\
\hline $\begin{array}{l}{ }^{1} \text { En } 4 \text { casos VIH (+) y en } 4 \text { casos V } \\
{ }^{2} \text { En } 4 \text { casos VIH (+) y en } 4 \text { caso VI } \\
{ }^{3} \text { En } 6 \text { casos no se determinó: } 4 \text { VIH } \\
{ }^{4} \text { En } 7 \text { casos no se determinó: } 2 \text { VIH }\end{array}$ & & & & \\
\hline
\end{tabular}

$22.7 \% p<0.001)$ y esto se debió a la alta proporción de pacientes VIH positivos con atrofia cerebral (32/60, 53.3\% vs. $1 / 24,4.2 \% p=0.003)$. Otras anormalidades observadas fueron: infarto cerebral (nueve casos, seis pacientes con sida), hidrocefalia (siete casos, cuatro pacientes con sida), calcificaciones cerebrales (cinco casos, tres pacientes VIH negativos), edema cerebral (tres casos, todos VIH positivos), aumento del realce meníngeo (dos casos, un paciente de cada 

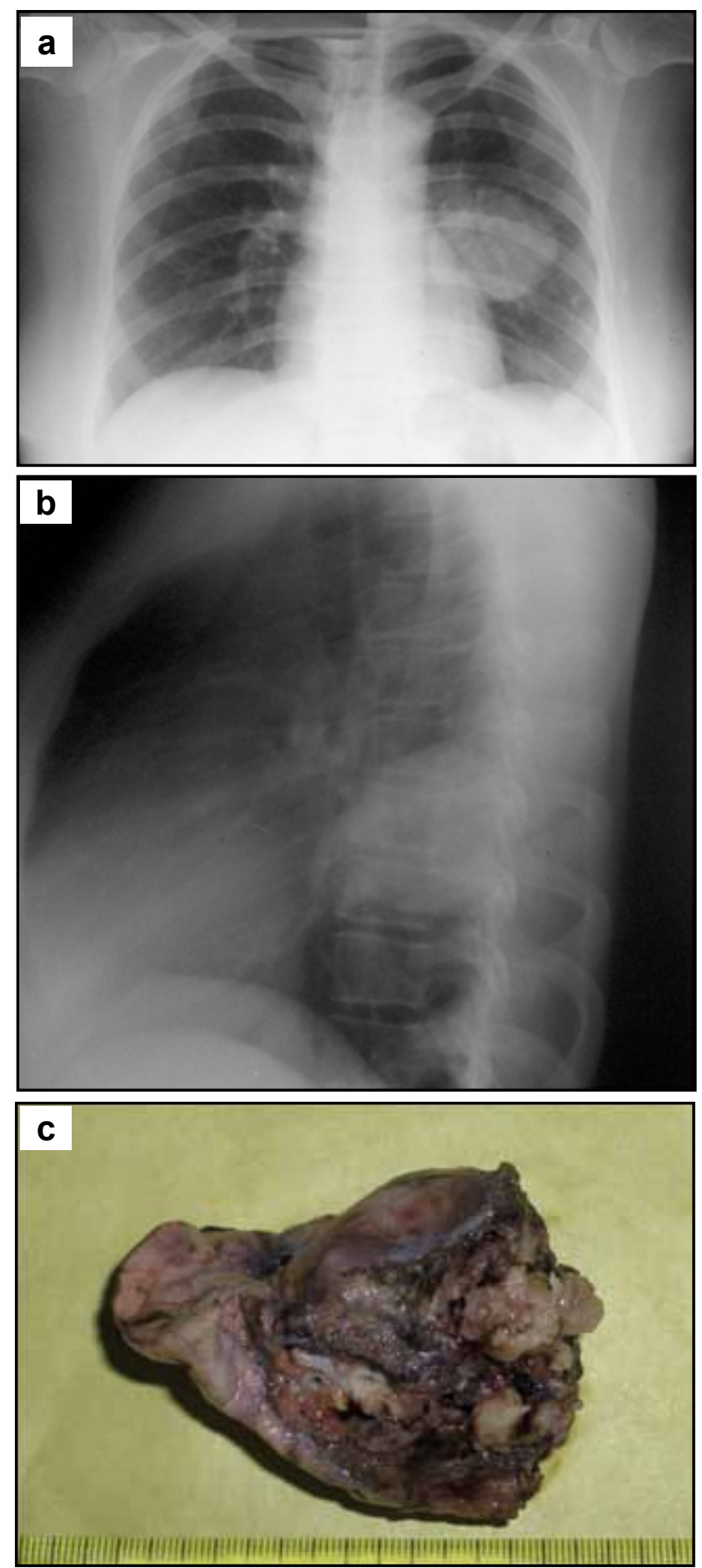

Figura 1. ( $a$ y b). Radiografía del tórax (proyecciones AP y lateral) que muestra un criptococoma pulmonar en el lóbulo inferior del pulmón izquierdo.(c).El mismo criptococoma resecado quirúrgicamente en una paciente VIH negativo.

grupo) y esquizencefalia de labio abierto parietal izquierda (un caso, hallazgo incidental de una patología congénita en un paciente VIH positivo). No se detectaron criptococomas encefálicos. Algunos pacientes tuvieron más de un hallazgo anormal en la TAC de cráneo. A cuatro pacientes (4.4\%), todos ellos VIH negativos, se les realizó RM de cerebro y todas fueron anormales; los hallazgos fueron: lesiones focales hipercaptantes en dos e hidrocefalia en dos.

Con excepción de los pacientes que no alcanzaron a recibir terapia antifúngica debido a la gravedad del padecimiento que los llevó rápidamente a la muerte (seis casos, cuatro VIH negativos), todos los demás fueron manejados inicialmente con anfotericina B a dosis de $0.7 \mathrm{mg} / \mathrm{kg} /$ día. En los sobrevivientes de esta fase de inducción que duró dos semanas, se consolidó el tratamiento con fluconazol 400 a $800 \mathrm{mg}$ por vía oral por ocho semanas. Algunos pacientes requirieron tratamiento más prolongados con anfotericina B debido a la falta de negativización del cultivo del LCR. El fluconazol se administró posteriormente como terapia profiláctica en los pacientes con sida. Los pacientes VIH negativos recibieron fluconazol por periodos prolongados de varios meses. A partir del año 2010, los pacientes recibieron el fluconazol a altas dosis $(800 \mathrm{mg}$ ) junto con la anfotericina B durante la fase de inducción. No se usaron corticosteroides. No se presentó el síndrome inflamatorio de restauración inmunológica (IRIS).

La hipertensión intracraneana fue tratada con punciones lumbares repetidas en el 56.4\% (22/39) de los pacientes y los pacientes VIH negativos recibieron esta modalidad terapéutica con mayor frecuencia ( $80 \%$ vs $41.7 \% p=0.02)$; en casos de difícil control se utilizó, además, el drenaje continuo de LCR mediante catéter raquídeo o la derivación quirúrgica lumboperitoneal.

Ocho pacientes fueron operados y hubo más cirugías en el grupo de pacientes VIH negativos (seis vs. dos) y los procedimientos realizados fueron los siguientes: derivación lumboperitoneal para manejo de la hipertensión intracraneana sin hidrocefalia (cuatro casos, tres, VIH negativos), derivación ventrículoperitoneal para tratamiento de hidrocefalia (tres casos, dos, VIH negativos) y resección de criptococoma pulmonar (un caso, VIH negativo) (Figura 1).

La letalidad hospitalaria fue significativamente mayor en los pacientes con sida ( $49.2 \%$ vs. $16 \%, p=0.004)$. En el análisis univariado, las siguientes variables se asociaron significativamente con letalidad hospitalaria: infección por el VIH $(\mathrm{p}=0.002)$, alteración de la conciencia al ingreso $(\mathrm{p}=0.002)$, no estar recibiendo TAR en los pacientes VIH positivos $(\mathrm{p}=0.008)$, convulsiones $(\mathrm{p}=0.013)$, y baja celularidad en el LCR ( $\mathrm{p}=0.015)$.

La supervivencia a los 120 días fue superior, en forma significativa, en los pacientes VIH negativos ( $82 \%$ vs $46 \%$, Log-Rank $p=0.0066$ y Wilcoxon $p=0.0093$ ) (Figura 2).

Un poco más de la tercera parte de los sobrevivientes quedaron con secuelas neurológicas en ambos grupos. Las secuelas más frecuentes fueron: epilepsia (seis casos, tres de cada grupo), pérdida de visión con atrofia óptica (cinco casos, tres VIH negativos), alteración de otros pares craneanos (cinco casos, tres pacientes con sida), déficit motor (cinco casos, tres pacientes con sida), deterioro cognitivo moderado (cuatro casos, tres con sida), alteración en el lenguaje (un caso VIH negativo), vejiga neurogénica (un caso sida) y 


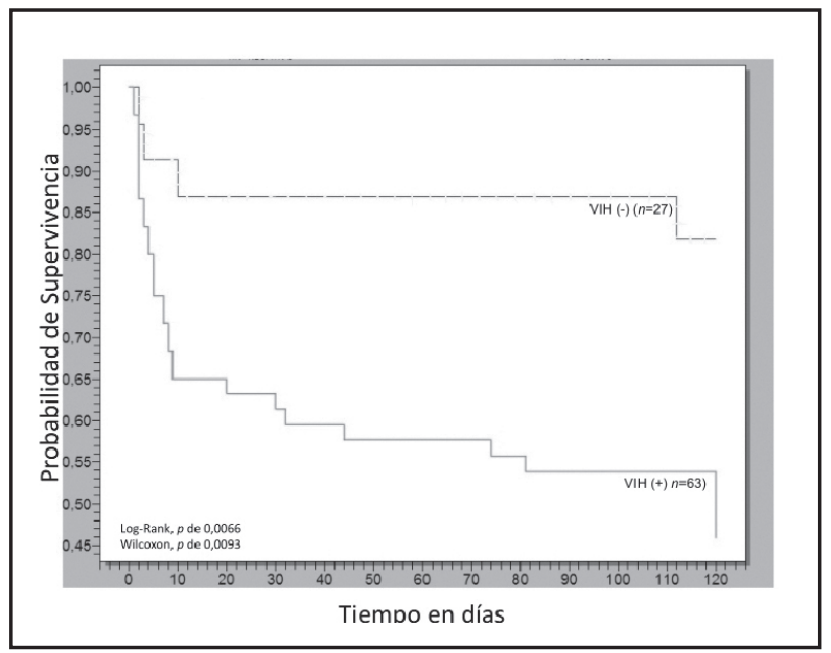

Figura 2. Curvas de supervivencia de los pacientes con criptococosis meníngea según el estado del VIH.

cefalea crónica (un caso, VIH negativo); algunos pacientes mostraron más de una secuela neurológica.

El porcentaje global de recaídas fue de $9.1 \%$ y no fue significativamente diferente en los dos grupos $11.1 \%$ en pacientes VIH positivos vs. $4 \%$ en pacientes VIH negativos).

\section{Discusión}

La criptococosis meníngea es un problema de salud pública en los países subsaharianos, en donde es alta la prevalencia de la infección por VIH (hasta un 20\%) y es, también, una de las principales causas de muerte en esta población (2). Más de medio millón de pacientes con criptococosis meníngea y sida mueren al año en dicha región africana (2). En Colombia, la incidencia en la población general de la criptococosis es mucho menor (2.4 casos por millón de habitantes), pero es mil veces más frecuente en los pacientes VIH positivos (tres casos por mil) (3). En esta serie, la infección por el VIH fue el factor de riesgo más frecuente $(70 \%)$, aunque notoriamente inferior comparado con la prevalencia nacional de $83.5 \%$ (3).

La incidencia de criptococosis en pacientes con sida ha venido disminuyendo en los países industrializados con acceso universal a la TAR y actualmente en estos países afecta a individuos con infección avanzada por el VIH y pobre acceso a los recursos en salud (7). En esta serie, similar a lo señalado en otros países (8-10), los pacientes con VIH, en su gran mayoría, presentaban un avanzado estado de inmunosupresión, evidenciado por el bajo número de células T CD4+. La criptococosis meníngea es la segunda infección oportunista del SNC en pacientes con sida en nuestra institución, después de la encefalitis por Toxoplasma gondii (11), similar a lo reportado en otras instituciones del mismo nivel en Colombia $(12,13)$.

Es llamativo que el $26.7 \%$ de los pacientes no tuvieron otro factor de riesgo y que entre los pacientes VIH negativos el $88.9 \%$ fueran aparentemente inmunocompetentes, hecho que se puede atribuir, en parte, a la alta prevalencia (60\%) de infección por $C$. gattii, especie que frecuentemente compromete a individuos sin factor de riesgo conocido $(5,14)$. Esta tendencia ha sido descrita en Asia y Oceanía. Por ejemplo, en Vietnam (15), en una serie de casos de pacientes VIH negativos se encontró un $81 \%$ sin factor de riesgo pero la prevalencia de criptococosis por C. gattii fue de sólo $30 \%$. En Hong Kong (16) $43.5 \%$ de los pacientes con criptococosis son aparentemente inmunocompetentes y la prevalencia de infección por C. gattii alcanza 37.5\%. Cifras similares se describen en Australia y Nueva Zelanda, en donde 31.2\% de los pacientes con criptococosis son aparentemente inmunocompetentes y $C$. gattii es el agente etiológico en $44 \%$ de los pacientes sin factor de riesgo (17). En los países en donde es baja la prevalencia de criptococosis por $C$. gattii, el porcentaje de pacientes sin factor de riesgo es mucho menor: Estados Unidos 18\% (7), Colombia 13.2\% (3), Taiwán 8.2\% (18) o Francia $5.2 \%$ (19). Contrario a lo anteriormente conocido, los brotes de criptococosis por C. gattii de aparición en la región de Vancouver (Columbia Británica, Canadá) en 1999 y en la región pacífica noroccidental de los Estados Unidos en 2004, afectaron frecuentemente a pacientes con algún tipo de factor de riesgo predisponente (38\% en Vancouver y $86 \%$ en los Estados Unidos) (20, 21).

En ambos grupos predominó el sexo masculino, aunque en proporción mayor en los pacientes con sida, hecho tradicionalmente descrito en esta micosis, aunque ocasionalmente se describen algunas series con predominio del sexo femenino $(15,22)$. La edad de los pacientes fue heterogénea, pero hay dos hechos para resaltar; por un lado la mayoría de pacientes con VIH eran adultos jóvenes (el 81\% tenía entre 20 y 39 años), hecho informado previamente $(8,23)$ y que refleja la epidemiología del sida en Colombia (3) y en los VIH negativos hubo un $29.6 \%$ de niños, hecho muy raro, con excepción de lo descrito en el norte y en el noreste del Brasil en donde han señalado una prevalencia de $24.4 \%$ (24) y $33 \%$ (25). No hay una explicación para este hecho, teniendo en mente que en Colombia la prevalencia de niños con criptococosis es $2.7 \%$ (3).

En esta serie no hubo diferencias significativas con relación a la procedencia. En Australia, han descrito que los pacientes con criptococosis por $C$. gattii son preferentemente de origen rural (17); vale la pena anotar que en el área urbana de Cúcuta, ciudad de donde provenía la mayoría de los pacientes, se ha recuperado a $C$. gattii del ambiente $(26,27)$.

En cuanto al tiempo de evolución, en los pacientes con sida la meningitis se presentó como un cuadro subagudo, mientras que en los pacientes VIH negativos tuvo una evolución crónica. Es probable, que en estos últimos, el diagnóstico fuera demorado debido a la falta de sospecha clínica, al no existir un factor de riesgo en casi todos ellos. En los pacientes con sida la criptococosis usualmente tiene un curso de varias semanas (28), aunque en ocasiones puede ser agudo fulminante (29). 
La cefalea constituye el síntoma cardinal entre las manifestaciones clínicas de la criptococosis meníngea, acompañada en muchos de ellos por náuseas y vómito (3). La mayoría de los pacientes tenía aumento de la presión intracraneana, documentada mediante la medición de la presión de apertura del LCR durante la punción lumbar, alcanzando una prevalencia de $83.3 \%$ en los pacientes VIH negativos. Este hallazgo, frecuentemente informado en otras series $(10,15,30)$, enfatiza la necesidad de hacer sistemáticamente esta medición durante el abordaje de un paciente con sospecha de meningitis. Como se infiere de estos hallazgos, la hipertensión intracraneana sin hidrocefalia debe orientar, en primer lugar, hacia el diagnóstico de criptococosis meníngea (31). La mayor presencia de cambios visuales (pérdida de visión y papiledema) en pacientes VIH negativos se correlaciona con el mayor porcentaje de pacientes con hipertensión intracraneana. La criptococosis extraneural fue, también, más frecuente en los pacientes VIH negativos, debido al compromiso pulmonar. Es posible que si se hubieran hecho más hemocultivos, se hubiera detectado un mayor porcentaje de fungemia en los pacientes con sida, que es lo esperado debido a la alta carga micótica que presentan estos pacientes (10). Hay que tener en cuenta que uno de cada ocho pacientes con sida y criptococosis meníngea tuvo un examen neurológico inicial normal; esto nos alerta acerca de la necesidad de considerar siempre la conveniencia de realizar estudio del LCR en el paciente con sida y cefalea, especialmente si las imágenes diagnósticas del cerebro no evidencian lesiones focales o hidrocefalia.

El estudio del LCR demostró, desde el punto de vista del análisis citoquímico, que los pacientes con sida tenían menos células y proteínas, hecho ya registrado (18) y explicable por su estado avanzado de inmunosupresión. El rendimiento diagnóstico de las pruebas diagnósticas en el LCR, a saber, tinta china, la determinación del antígeno capsular y del cultivo, fueron similarmente altos en ambos grupos. En los pacientes VIH positivos, usualmente, presentan mayor positividad en estas pruebas debido a la mayor carga micótica $(3,18)$.

C. neoformans var. grubii ha sido descrito, en todo el mundo, como el principal agente etiológico de la criptococosis meníngea en los pacientes VIH positivos (1), en esta serie fue el único. Al contrario, en los pacientes VIH negativos predominó $C$. gattii $(60 \%)$, hecho conocido en el departamento Norte de Santander $(4,32)$ y que contrasta grandemente con la prevalencia de $C$. gattii en los pacientes VIH negativos en Colombia, en donde alcanza solamente $17.4 \%$ (3).

El patrón molecular predominante en esta serie es el VNI, hecho reportado mundialmente (33-39) y prácticamente el único recuperado en los pacientes con sida, hecho también descrito $(33,37)$. Entre los pacientes VIH negativos en los cuales se aisló $C$. gattii, llama la atención el predominio del patrón VGII (50\%). Este mismo patrón molecular es el único aislado en la epidemia de Vancouver, tanto de los pacientes como del ambiente y se ha caracterizado por su gran virulencia (40).

Frecuentemente, los pacientes con criptococosis meníngea presentan anormalidades pulmonares evidenciadas en la radiografía del tórax. En esta serie, un tercio de los pacientes tenían radiografías anormales, siendo el hallazgo más frecuente los infiltrados pulmonares, igual a lo informado en el estudio nacional (3). En los pacientes con criptococosis pulmonar confirmada los hallazgos más frecuentes son los nódulos o las masas, seguidos por las consolidaciones pulmonares con broncograma aéreo. Los pacientes infectados por el VIH tienden a presentar más cavitaciones con nódulos y consolidaciones parenquimatosas, de mayor extensión, que los pacientes VIH negativos (41). No olvidar que puede existir la tuberculosis pulmonar como comorbilidad en los pacientes con criptococosis meníngea y sida (3).

En cuanto a las imágenes diagnósticas del cerebro, el examen más usado fue la TAC de cráneo y fue anormal en la mayoría de los pacientes, especialmente en los pacientes con sida. La RM de cerebro fue anormal en los cuatro pacientes VIH negativos evaluados. La anormalidad más frecuentemente vista fue la atrofia cerebral, que en los pacientes VIH positivos se explica principalmente por la infección retroviral. Otras anormalidades registradas fueron los infartos cerebrales, la hidrocefalia, el edema cerebral y el aumento del realce meníngeo, similar a lo descrito previamente (42).

A pesar de la alta prevalencia de criptococosis por $C$. gattii no se detectaron criptococomas cerebrales. Tampoco, se informaron pseudoquistes gelatinosos que corresponden a espacios de Virchow-Robin dilatados (43). Las lesiones parenquimatosas encefálicas detectadas en las neuroimágenes al ingreso se asocian con un mal pronóstico tanto en los pacientes VIH positivos y VIH negativos (44) como en los sometidos a trasplantes de órgano sólido (45).

El tratamiento antifúngico de los pacientes se fundamentó, durante los primeros años, en la evidencia clínica existente $(46,47)$ y a partir del año 2000 en la guía internacional de manejo de la criptococosis (48). La terapia de inducción se hizo sólo con anfotericina $\mathrm{B}$, ante la falta de 5-fluocitosina en el país, seguido de una fase de consolidación con fluconazol. Sólo los últimos pacientes recibieron tratamiento inicial de anfotericina B y fluconazol, de acuerdo con las recomendaciones de las últimas guías de manejo del año 2010 (49).

El tratamiento de la hipertensión intracraneana sin hidrocefalia se hizo a partir del año 2000 con punciones lumbares diarias, teniendo en cuenta las recomendaciones dadas para mejorar el pronóstico vital y de secuelas de los pacientes con criptococosis meníngea (50). Es sabido que la falta de un manejo agresivo de esta frecuente complicación se asocia con pobres resultados (51).

Casi todas las cirugías fueron encaminadas al tratamiento de la hipertensión intracraneana con o sin hidrocefalia y con mayor frecuencia en los pacientes inmunocompetentes. Sólo a una paciente se le hizo resección de un criptococoma 
pulmonar (Figura 1). En los pacientes sin alteraciones aparentes del sistema inmune, la demora en el diagnóstico de la criptococosis meníngea se ha asociado con presencia de hidrocefalia y necesidad de realizar cirugías de derivación del LCR (52). Cuatro pacientes sin hidrocefalia requirieron derivación lumboperitoneal del LCR debido a la hipertensión intracraneana incontrolable con punciones lumbares diarias o con colocación de catéter raquídeo. Este tipo de cirugía es necesaria para evitar la herniación cerebral o la lesión definitiva de los nervios ópticos (53). La derivación ventriculoperitoneal del LCR está indicada en el manejo de la hidrocefalia (54) y algunos también la recomiendan para el tratamiento de la hipertensión intracraneana sin hidrocefalia $(55,56)$.

La letalidad hospitalaria de esta serie fue alta (39.6\%) y mayor en los pacientes con sida $(49.2 \%)$; los pacientes VIH negativos tuvieron un mejor resultado (16\%). La letalidad por criptococosis meníngea sigue siendo inaceptablemente alta en el mundo (Tabla 3 ). En países como Estados Unidos $(7,47)$ y Francia (69) oscila entre 11 y $21 \%$. Similares cifras de letalidad hospitalaria se obtienen en pacientes VIH positivos atendidos en hospitales universitarios de Sudáfrica $(52,57,58)$, Botsuana (61), Camboya (67) y Corea del Sur (10). Sin embargo, estas cifras son superiores al $30 \%$

Tabla 3. Letalidad hospitalaria y supervivencia de los pacientes con criptococosis meníngea en el mundo.

\begin{tabular}{|c|c|c|c|}
\hline $\begin{array}{l}\text { País } \\
\text { Referencia }\end{array}$ & Tipo de población y tratamiento & $\begin{array}{c}\text { Letalidad } \\
\text { hospitalaria }(\%)\end{array}$ & $\begin{array}{c}\text { Supervivencia } \\
(\%)(\text { tiempo) }\end{array}$ \\
\hline $\begin{array}{l}\text { SUDÁFRICA } \\
\text { KwaZulu-Natal } \\
\text { Lessells, } 2011 \text { (57) }\end{array}$ & $\begin{array}{l}\text { VIH (+) Hospital rural. } \\
\text { La mayoría con solo FCZ. Muy pocos con TAR }\end{array}$ & 40.5 & 10.8 (2 años) \\
\hline $\begin{array}{l}\text { Ciudad del Cabo } \\
\text { Bicanic, } 2007 \text { (58) }\end{array}$ & $\begin{array}{l}\text { VIH }(+) \\
\text { AmB seguido de FCZ } \\
\text { sin TAR vs } \\
\text { con TAR }\end{array}$ & 17 ( 2 semanas) & $\begin{array}{c}63 \text { (10 semanas) } \\
35 \text { (1 año) } \\
24 \text { ( } 1 \text { año }) \\
59(1 \text { año }) \\
(p=0.03)\end{array}$ \\
\hline Bicanic, 2008 (59) & $\begin{array}{l}\text { VIH }(+) \sin \text { TAR } \\
\text { AmB } 0,7 \mathrm{mg} / \mathrm{kg}+5 \mathrm{FC} \text { vs } \\
\text { AmB } 1 \mathrm{mg} / \mathrm{kg}+5 \mathrm{FC}\end{array}$ & $\begin{array}{l}6 \\
3 \\
9\end{array}$ & $\begin{array}{l}76 \text { (10 semanas) } \\
79 \text { (10 semanas) } \\
74 \text { (10 semanas) }\end{array}$ \\
\hline Jarvis, $2010(60)$ & $\begin{array}{l}\text { VIH }(+) \\
\text { AmB seguido de FCZ } \\
\text { sin TAR vs } \\
\text { con TAR }\end{array}$ & $\begin{array}{l}31 \\
29\end{array}$ & $\begin{array}{l}24 \text { (1 año) } \\
59(1 \text { año }) \\
(p=0.03)\end{array}$ \\
\hline $\begin{array}{l}\text { BOTSUANA } \\
\text { Bisson, } 2008 \text { (61) }\end{array}$ & $\begin{array}{l}\text { VIH (+) AmB seguido de fluconazol } \\
\text { sin TAR vs } \\
\text { con TAR }\end{array}$ & $\begin{array}{c}17 \\
21 \\
8\end{array}$ & \\
\hline Steele, $2010(62)$ & $\begin{array}{l}\text { VIH (+) C. neoformans vs } \\
\text { VIH (+) C. gattii }\end{array}$ & $\begin{array}{l}19 \\
17\end{array}$ & \\
\hline $\begin{array}{l}\text { UGANDA } \\
\text { Kambugu, } 2008 \text { (63) }\end{array}$ & $\begin{array}{l}\text { VIH }(+) \text { AmB } \\
\text { era pre- TAR vs } \\
\text { era TAR }\end{array}$ & $\begin{array}{l}41 \\
20\end{array}$ & $\begin{array}{l}\text { No evaluada } \\
41 \text { ( } 6 \text { meses })\end{array}$ \\
\hline $\begin{array}{l}\text { ZIMBAWE } \\
\text { Makadzange, } 2010 \text { (64) }\end{array}$ & $\begin{array}{l}\text { VIH (+) sin TAR FCZ } 800 \mathrm{mg} / \mathrm{d} \\
\text { inicio temprano TAR ( } 72 \text { horas) vs } \\
\text { inicio tardío TAR ( } 10 \text { semanas) }\end{array}$ & & $\begin{array}{l}27 \text { ( } 3 \text { años }) \\
12(3 \text { años }) \\
46(3 \text { años }) \\
(p<0.006)\end{array}$ \\
\hline $\begin{array}{l}\text { ZAMBIA } \\
\text { Mwaba, } 2001(65)\end{array}$ & $\begin{array}{l}\text { VIH }(+) \sin \text { TAR } \\
\text { sin FCZ vs } \\
\text { con tratamiento }\end{array}$ & & $\begin{array}{c}0 \text { (7 semanas }) \\
0 \text { (24 semanas })\end{array}$ \\
\hline $\begin{array}{l}\text { TAILANDIA } \\
\text { Chottanapund, } 2007 \text { (66) }\end{array}$ & $\begin{array}{l}\text { VIH (+) AmB seguido de FCZ } \\
\text { sin TAR vs } \\
\text { con TAR }\end{array}$ & & $\begin{array}{l}55,3(1 \text { año }) \\
92,8(1 \text { año }) \\
(p<0.01)\end{array}$ \\
\hline Jongwutiwes, 2008 (8) & $\begin{array}{l}\text { VIH (+) y VIH (-) AmB en la mayoría } \\
\text { VIH (-) vs } \\
\text { VIH (+) }\end{array}$ & $\begin{array}{l}24.2 \\
34.5 \\
22.2\end{array}$ & \\
\hline
\end{tabular}


Tabla 3. (Continuación). Letalidad hospitalaria y supervivencia de los pacientes con criptococosis meníngea en el mundo.

\begin{tabular}{|c|c|c|c|}
\hline $\begin{array}{l}\text { País } \\
\text { (Referencia) }\end{array}$ & Tipo de población y tratamiento & $\begin{array}{c}\text { Letalidad hospitalaria } \\
\%\end{array}$ & $\begin{array}{l}\text { Supervivencia } \\
\% \text { (tiempo) }\end{array}$ \\
\hline $\begin{array}{l}\text { CAMBOYA } \\
\text { Micol, } 2007 \text { (67) } \\
\text { Espié, (2010) (68) }\end{array}$ & $\begin{array}{l}\text { VIH (+) AmB seguido de FCZ } \\
\text { VIH (+) } 2,4 \% \text { con TAR }\end{array}$ & $\begin{array}{c}9.8 \\
38.7\end{array}$ & 63 (12 semanas) \\
\hline $\begin{array}{l}\text { INDIA } \\
\text { Majunder, } 2011 \text { (9) }\end{array}$ & VIH (+) Algunos con TAR & 36.7 & \\
\hline $\begin{array}{l}\text { CHINA } \\
\text { Zhu, } 2010 \text { (52) }\end{array}$ & VIH (-) La mayoría AmB & 19.6 & \\
\hline $\begin{array}{l}\text { HONG KONG } \\
\text { Lui, } 2006(16)\end{array}$ & $\begin{array}{l}\text { VIH (-) La mayoría AmB con o sin 5FC } \\
\text { VIH (-) con otro factor de riesgo vs } \\
\text { VIH (-) aparentemente inmunocompetente }\end{array}$ & $\begin{array}{c}62.5 \\
(p<0.05) \\
18.7\end{array}$ & \\
\hline $\begin{array}{l}\text { TAIWAN } \\
\text { Lee, } 2011 \text { (18) }\end{array}$ & $\begin{array}{l}\text { VIH (+) y VIH (-) AmB } \\
\text { VIH (+) vs } \\
\text { VIH (-) }\end{array}$ & $\begin{array}{l}29.7 \\
33.3\end{array}$ & \\
\hline $\begin{array}{l}\text { COREA DEL SUR } \\
\text { Lee, } 2011(10)\end{array}$ & $\begin{array}{l}\text { VIH (+) y VIH (-) AmB seguido de FCZ } \\
\text { VIH (+) vs } \\
\text { VIH (-) }\end{array}$ & $\begin{array}{c}10 \\
9 \\
11.1\end{array}$ & \\
\hline $\begin{array}{l}\text { VIETNAM } \\
\text { Chau, } 2010(15)\end{array}$ & $\begin{array}{l}\mathrm{VIH}(-) 81 \% \text { sin factor de riesgo } \mathrm{AmB}+5 \mathrm{FC} \\
\text { C. neoformans vs } \\
\text { C. gattii }\end{array}$ & $\begin{array}{l}19 \\
24 \\
10\end{array}$ & \\
\hline $\begin{array}{l}\text { FRANCIA } \\
\text { Lortholary, } 2006 \text { (69) }\end{array}$ & $\begin{array}{l}\text { VIH (+) con TAR } \\
\text { VIH (+) pre TAR vs } \\
\text { VIH (+) con TAR }\end{array}$ & $\begin{array}{l}29 \\
18\end{array}$ & $\begin{array}{l}43.4 \text { ( } 3 \text { meses }) \\
\text { 36.2/100 pacientes/ año } \\
84.7 / 100 \text { pacientes/año }\end{array}$ \\
\hline $\begin{array}{l}\text { ESTADOS UNIDOS } \\
\text { van der Horst, } 1999 \text { (47) } \\
\text { Mirza, } 2003 \text { (7) }\end{array}$ & $\begin{array}{l}\text { VIH (+) excluidos los casos graves AmB }+5 \text { FC seguido de fluconazol } \\
\text { VIH (+) vs } \\
\text { VIH (-) }\end{array}$ & $\begin{array}{l}10.9 \\
11 \\
21\end{array}$ & \\
\hline $\begin{array}{l}\text { BRASIL } \\
\text { Rio de Janeiro } \\
\text { Leimann, } 2008 \text { (70) }\end{array}$ & $\mathrm{VIH}(+) 61,2 \%$ & 51.8 & \\
\hline $\begin{array}{l}\text { Salvador } \\
\text { Darzé, } 2000 \text { (25) }\end{array}$ & Sin factor de riesgo $85,6 \%$ & 42.7 & \\
\hline $\begin{array}{l}\text { Uberlandia } \\
\text { Moreira, } 2006(71)\end{array}$ & $\begin{array}{l}\text { VIH (+) } 81,3 \% \text {, } \\
\text { criptococosis meníngea } 56,3 \% \\
\text { C. neoformans vs } \\
\text { C. gattii }\end{array}$ & $\begin{array}{l}72.9 \\
75.3 \\
42.9\end{array}$ & 59.3 \\
\hline $\begin{array}{l}\text { Nacional } \\
\text { Severo, } 2009(72)\end{array}$ & Niños & 40.7 & \\
\hline $\begin{array}{l}\text { COLOMBIA } \\
\text { Lizarazo, } 2001(73)\end{array}$ & $\begin{array}{l}\text { VIH (+) vs } \\
\text { VIH (-) }\end{array}$ & & $\begin{array}{l}42 \text { (6 meses) } \\
47 \text { (6 meses) }\end{array}$ \\
\hline Lizarazo, 2000 (4) & C. gattii & 35 & \\
\hline $\begin{array}{l}\text { CÚCUTA } \\
\text { Lizarazo (esta serie) }\end{array}$ & $\begin{array}{l}\text { VIH (+) vs } \\
\text { VIH (-) }\end{array}$ & $\begin{array}{c}49.2(p=0.004) \\
16\end{array}$ & $\begin{array}{c}46 \text { ( } 4 \text { meses }) \\
82 \text { (4 meses) }(p=0.0066)\end{array}$ \\
\hline $\begin{array}{l}\text { INTERNACIONAL } \\
\text { Singh, } 2008 \text { (45) }\end{array}$ & Trasplantados & 20 & \\
\hline $\mathrm{FCZ}=$ fluconazol & $5 \mathrm{FC}=5$ fluorocitosina & ricina $\mathrm{B}$ & \\
\hline
\end{tabular}


en pacientes atendidos en área rural de Sudáfrica (57) o en poblaciones con poco acceso a la TAR, en Camboya (68) y la India (9), e inexplicablemente en Brasil $(70,71)$ en donde el cubrimiento de la TAR es universal en la población con sida. En pacientes VIH negativos las cifras reportadas van desde $11 \%$ en Corea del Sur (10) hasta $42.7 \%$ en Brasil (25), con valores intermedios en Hong Kong (16), Vietnam (15), China (52), Estados Unidos (7), Taiwán (18) y Tailandia (8). En pacientes pediátricos brasileños (72) la letalidad alcanza $40.7 \%$ y en los trasplantados de órganos sólidos (45) $20 \%$.

La alta letalidad en nuestros pacientes VIH positivos se puede explicar por varios factores. Entre ellos, el poco porcentaje que recibían TAR, el avanzado estado de inmunosupresión y el grave compromiso de la conciencia al ingreso de muchos de ellos. La letalidad en los pacientes VIH negativos de nuestra serie está dentro del rango bajo de lo publicado (Tabla 3 ) y el mejor resultado pudiera explicarse por la ausencia de factor riesgo en $88.9 \%$, lo que implica una mejor condición inmunológica. Las variables asociadas significativamente con letalidad hospitalaria en esta serie fueron la infección por el VIH, la alteración del estado de conciencia al ingreso, la falta de TAR en los pacientes VIH positivos, las convulsiones y la pobre respuesta celular en el LCR (<20 leucocitos/mL). Clásicamente, antes de la aparición de la pandemia por el VIH, los factores de mal pronósticos descritos fueron; enfermedad subyacente (malignidad hematológica o uso de corticosteroides), ausencia de cefalea, estado mental anormal, alta carga del hongo demostrada por la prueba de la tinta china positiva y por títulos elevados del antígeno capsular en el LCR, la pobre respuesta inflamatoria $(<20$ células $/ \mathrm{mL})$ y la elevación de la presión intracraneana $(74,75)$. En pacientes con infección por el VIH también se han señalado como factores de mal pronóstico la alteración del estado mental, la alta carga micótica (determinada por cultivos cuantitativos y los títulos altos del antígeno capsular en el LCR), las anormalidades en el examen neurológico y en las imágenes diagnósticas del SNC, la elevación de la presión intracraneana y la baja celularidad del LCR $(76,77)$.

La supervivencia de nuestros pacientes con sida es baja (46\% a 4 meses) y denota las dificultades de acceso a la TAR. En países con la misma limitación los resultados de supervivencia son pobres (Tabla 3 y Figura 2).

La falta de pacientes con IRIS en esta serie probablemente se deba a que la TAR se inicia, usualmente, varias semanas después de tratada la criptococosis meníngea. La instauración temprana de la TAR en esta población es uno de los factores asociados con el IRIS (78).

Las secuelas observadas fueron muy frecuentes, en más de la tercera parte de los sobrevivientes. Entre las más frecuentes, están las derivadas de la hipertensión intracraneana crónica como son la atrofia óptica con la respectiva pérdida visual. Es conocida $(4,5)$ la alta frecuencia de esta secuela en pacientes afectados por C. gattii.
Las recaídas observadas, en mayor porcentaje en los pacientes VIH positivos (11.1\% vs $4 \%$ ), probablemente esté reflejando una inadecuada profilaxis secundaria con fluconazol (77).

En conclusión, este trabajo demuestra que los pacientes VIH positivos con criptococosis meníngea tienen una cifra de letalidad muy alta. Por lo tanto, se hace necesaria la detección temprana de esta infección oportunista aun antes de que aparezcan los síntomas $(80,81)$. El desarrollo de una prueba de flujo lateral para la determinación del antígeno capsular en plasma y suero, representa un gran avance en ese sentido debido a su bajo costo, su fácil implementación y su alta sensibilidad y especificidad diagnóstica $(82,83)$. La alta prevalencia de $C$. gattii y de niños en los pacientes VIH negativos constituyen un reto investigativo cuya respuesta probablemente esté en el ambiente. Además, la aparición de cepas hipervirulentas de $C$. gattii en la isla de Vancouver y regiones aledañas de la Columbia Británica en Canadá (84) y en el noroeste de los Estados Unidos (85) refuerzan la necesidad de determinar el tipo de especie que está circulando en nuestros pacientes debido a las implicaciones clínicas y epidemiológicas.

\section{Agradecimientos}

A Carmen Yepes y a Iván Velandia por su colaboración en la recolección de la información.

\section{Referencias}

1. Jarvis JN, Harrison TS. HIV-associated cryptococcal meningitis. AIDS 2007; 21: 2119-29.

2. Park BJ, Wannemuehler KA, Marston BJ, Govender N, Pappas PG, Chiller TM. Estimation of the current global burden of cryptococcal meningitis among persons living with HIV/AIDAS. AIDS 2009; 23: 525-30.

3. Lizarazo J, Linares M, de Bedout C, Restrepo A, Agudelo CI, Castañeda E y Grupo Colombiano para el Estudio de la Criptococosis. Estudio clínico y epidemiológico de la criptococosis en Colombia: resultados de nueve años de la encuesta nacional, 1997-2005. Biomédica 2007; 27: 94-109.

4. Lizarazo J, Mendoza M, Palacios D, Vallejo A, Bustamante A, Ojeda E, Restrepo A, Castañeda E. Criptococosis ocasionada por Cryptococcus neoformans variedad gattii. Acta Med Colomb 2000; 25:171-8.

5. Seaton RA, Verma N, Naraqi S, Wembri JP, Warrell DA. Visual loss in immunocompetent patients with Cryptococcus neoformans var. gattii meningitis. Trans R Soc Trop Med Hyg 1997; 91: 44-9.

6. Escandón P, Montilla A. Tipificación molecular de aislamientos del complejo Cryptococcus neoformans/Cryptococcus gattii. Infectio 2010; 14: 127-30.

7. Mirza SA, Phelan M, Rimland D, Craviss E, Hamill R, Brandt ME, Gardner T, Sattah M, de León GP, Baughman W, Haijeh RA. The changing epidemiology of cryptococcosis: an update from population-based active surveillance in 2 large metropolitan areas, 1992-2000. Clin Infect Dis 2003; 36: 789-94.

8. Jongwutiwes U,Sungkanuparph S, Kiertiburanakul S. Comparison of clinical features and survival between cryptococcosis in human immunodeficiency virus HIV-positive and HIV-negative patients. Jpn J Infect Dis 2008; 61: 111-5.

9. Majumder S, Mandal SK, Bandyopadhyay D. Prognostic markers in AIDSrelated cryptococcal meningitis. J Assoc Physicians India 2011; 59: 152-4.

10. Lee SJ, Choi HK, Son J, Kim KH, Lee SH. Cryptococcal meningitis in patients with or without human immunodeficiency virus: experience in a tertiary hospital. Yonsei Med J. 2011; 52: 482-7.

11. Lizarazo J, Castro F, de Arco M, Chaves O, Peña Y. Infecciones oportunistas del sistema nervioso central en pacientes con VIH atendidos en el Hospital Universitario Erasmo Meoz de Cúcuta (1995-2005). Infectio 2006; 10: 226-231.

12. Ávila G, González G. Algunas manifestaciones neurológicas del síndrome 
de inmunodeficiencia adquirida (sida) en pacientes del Hospital Universitario Hernando Moncaleano Perdomo de Neiva 2001-2004. Acta Neurol Colomb 2007; 23: 90-4.

13. Mantilla JC, Cárdenas N. Hallazgos neuropatológicos de la infección por VIH-sida: estudio de autopsias en el Hospital Universitario de Santander, Bucaramanga, Colombia. Colombia Médica 2009; 40: 422-31.

14. Mitchell DH, Sorrell TC, Allworth AM, Heath CH, McGregor AR, Papanaoum K, Richards MJ, Gottlieb T. Cryptococcal disease of the CNS in immunocompetent hosts: influence of cryptococcal variety on clinical manifestations and outcome. Clin Infect Dis 1995; 20: 611-6.

15. Chau TT, Mai NH, Phu NH, Nghia HD, Chuong LV, Sinh DX, Duong VA, Diep PT, Campbell JI, Baker S, Hien TT, Lalloo DG, Farrar JJ, Day JN. A prospective descriptive study of cryptococcal meningitis in HIV uninfected patients in Vietnam - high prevalence of Cryptococcus neoformans var. grubii in the absence of underlying disease. BMC Infect Dis 2010; 10: 199

16. Lui G, Lee N, Ip M, Choi KW, Tso YK, Lam E, Chau S, Lai R, Cockram CS. Cryptococcosis in apparently immunocompetent patients. QJM 2006; 99: 143-51.

17. Chen S, Sorrell T, Nimmo G, Speed B, Currie B, Ellis D, Marriott D, Pfeiffer T, Parr D, Byth K. Epidemiology and host- and variety-dependent characteristics of infection due to Cryptococcus neoformans in Australia and New Zealand. Australasian Cryptococcal Study Group. Clin Infect Dis 2000; 31: 499-508.

18. Lee YC, Wang JT, Sun HY, Chen YC. Comparisons of clinical features and mortality of cryptococcal meningitis between patients with and without human immunodeficiency virus infection. J Microbiol Immunol Infect 2011; 44: 33845 .

19. Dromer F, Mathoulin S, Dupont B, Laporte A. Epidemiology of cryptococcosis in France: a 9-year survey (1985-1993). French Cryptococcosis Study Group. Clin Infect Dis 1996; 23: 82-90.

20. Galanis E, Macdougall L. Epidemiology of Cryptococcus gattii, British Columbia, Canada, 1999-2007. Emerg Infect Dis 2010; 16: 251-7.

21. Harris JR, Lockhart SR, Debess E, Marsden-Haug N, Goldoft M, Wohrle R, Lee S, Smelser C, Park B, Chiller T. Cryptococcus gattii in the United States: clinical aspects of infection with an emerging pathogen. Clin Infect Dis 2011; 53: 1188-95.

22. Kiertiburanakul S, Wirojtananugoon S, Pracharktam R, Sungkanuparph S. Cryptococcosis in human immunodeficiency virus-negative patients. Int J Infect Dis 2006; 10: 72-8.

23. Imwidthaya P, Poungvarin N. Cryptococcosis in AIDS. Postgrad Med J 2000; 76: $85-8$.

24. Corrêa Mdo P, Oliveira EC, Duarte RR, Pardal PP, Oliveira Fde M, Severo LC. Criptococose em crianças no Estado do Pará, Brasil. Rev Soc Bras Med Trop 1999; 32: 505-8.

25. Darzé C, Lucena R, Gomes I, Melo A. Características clínicas laboratoriais de 104 casos de meningoencefalite criptocócica. Rev Soc Bras Med Trop 2000; 33: 21-6.

26. Castañeda A, Huérfano S, Rodríguez MC, Castañeda E. Recuperación de Cryptococcus neoformans var. gattii serotipo $\mathrm{C}$ a partir de detritos de almendros. Biomédica 2001; 21: 70-4.

27. Firacative C, Torres GA, Rodríguez MC, Escandón P. Primer aislamiento ambiental de Cryptococcus gattii serotipo B, en Cúcuta, Colombia. Biomédica 2011; 31: 118-23.

28. Warkentien T, Crum-Cianflone NF. An update on Cryptococcus among HIVinfected patients. Int J STD AIDS 2010; 21: 679-84.

29. Angstwurm K, Sokolowska-Koehler W, Stadelmann C, Schielke E, Weber JR. Fulminant cryptococcal meningitis as presenting feature in a patient with AIDS. Eur J Neurol 2004; 11: 353-4

30. Bicanic T, Brouwer AE, Meintjes G, Rebe K, Limmathurotsakul D, Chierakul W, Teparrakkul P, Loyse A, White NJ, Wood R, Jaffar S, Harrison T. Relationship of cerebrospinal fluid pressure, fungal burden and outcome in patients with cryptococcal meningitis undergoing serial lumbar punctures. AIDS 2009; 23: 701-6.

31. Lizarazo J. Medición de la presión de apertura del LCR durante la punción lumbar (Carta al Editor). Rev Fac Med Univ Nac Colomb 2006; 54: 66-7.

32. Lizarazo J, Rodríguez MC, Ordóñez N, Vargas JJ, Castañeda E. Meningitis por Cryptococcus en el Hospital Erasmo Meoz de Cúcuta. Acta Neurol Colomb 1995; 11: 259-67.
33. Matsumoto MT. Fusco-Almeida AM. Baeza LC. Melhem MSC, MendesGiannini MJS. Genotyping, serotyping and determination of mating-type of Cryptococcus neoformans clinical isolates from São Paulo State, Brazil. Rev Inst Med trop S Paulo 2007; 49: 41-47.

34. Feng X, Yao Z, Ren D, Wanqing Liao W, Wu J. Genotype and mating type analysis of Cryptococcus neoformans and Cryptococcus gattii isolates from China that mainly originated from non-HIV-infected patients. FEMS Yeast Res 2008; 8: 930-938.

35. Escandón P, Sánchez A, Martínez M, Meyer W, Castañeda E. Molecular epidemiology of clinical and environmental isolates of the Cryptococcus neoformans species complex reveals a high genetic diversity and the presence of the molecular type VGII mating type a in Colombia. FEMS Yeast Res 2006; 6: $625-35$.

36. Liaw SJ, Wu HC, Hsueh PR. Microbiological characteristics of clinical isolates of Cryptococcus neoformans in Taiwan: serotypes, mating types, molecular types, virulence factors, and antifungal susceptibility. Clin Infect Dis 2010; 16: 696-703.

37. Casali AK, Goulart L, Rosa e Silva LK, Ribeiro AM, Amaral AA, Alves SH, Schrank A, Meyer W, Vainstein MH. Molecular typing of clinical and environmental Cryptococcus neoformans isolates in the Brazilian state Rio Grande do Sul. FEMS Yeast Res 2003; 3: 405-15.

38. Chen J, Varma A, Diaz MR, Litvintseva AP, Wollenberg KK, Kwon-Chung KJ. Cryptococcus neoformans strains and infection in apparently immunocompetent patients, China. Emerg Infect Dis 2008; 14: 755-62.

39. Jain N, Wickes BL, Keller SM, Fu J, Casadevall A, Jain P, Ragan MA, Banerjee U, Fries BC. Molecular epidemiology of clinical Cryptococcus neoformans strains from India. J Clin Microbiol 2005; 43: 5733-42.

40. Kidd SE, Hagen F, Tscharke RL, Huynh M, Bartlett KH, Fyfe M, MacDougall L, Boekhout T, Kwon-Chung KJ, Meyer W. A rare genotype of Cryptococcus gattii caused the cryptococcosis outbreak on Vancouver Island (British Columbia, Canada). Proc Natl Acad Sci USA 2004; 101: 17258-63.

41. Chang WC, Tzao C, Hsu HH, Lee SC, Huang KL, Tung HJ, Chen CY. Pulmonary cryptococcosis: comparison of clinical and radiographic characteristics in immunocompetent and immunocompromised patients. Chest 2006; 129: 333-40.

42. Popovich MJ, Arthur RH, Helmer E. CT of intracranial cryptococcosis. AJR Am J Roentgenol 1990; 154: 603-6.

43. Corti M, Villafañe MF, Negroni R, Arechavala A, Maiolo E. Magnetic resonance imaging findings in AIDS patients with central nervous system cryptococcosis. Rev Iberoam Micol 2008; 25: 211-4.

44. Dromer F, Mathoulin-Pélissier S, Launay O, Lortholary O; French Cryptococcosis Study Group. Determinants of disease presentation and outcome during cryptococcosis: the CryptoA/D study. PLoS Med 2007; 4: e21.

45. Singh N, Lortholary O, Dromer F, Alexander BD, Gupta KL, John GT, del Busto R, Klintmalm GB, Somani J, Lyon GM, Pursell K, Stosor V, Munoz P, Limaye AP, Kalil AC, Pruett TL, Garcia-Diaz J, Humar A, Houston S, House AA, Wray D, Orloff S, Dowdy LA, Fisher RA, Heitman J, Wagener MM, Husain S; Cryptococcal Collaborative Transplant Study Group. Central nervous system cryptococcosis in solid organ transplant recipients: clinical relevance of abnormal neuroimaging findings. Transplantation 2008; 86: 647 51

46. Bennett JE, Dismukes WE, Duma RJ, Medoff G, Sande MA, Gallis H, Leonard J, Fields BT, Bradshaw M, Haywood H, McGee ZA, Cate TR, Cobbs CG, Warner JF, Alling DW. A comparison of amphotericin B alone and combined with flucytosine in the treatment of cryptococcal meningitis. $N$ Engl J Med 1979; 301: 126-31.

47. van der Horst C, Saag MS, Cloud GA, Hamill RJ, Graybill JR, Sobel JD, Johnson PC, Tuazon CU, Kerkering T, Moskovitz BL, Powderly WG, Dismukes WE. Treatment of cryptococcal meningitis associated with the acquired immunodeficiency syndrome. N Engl J Med 1997; 337: 15-21.

48. Saag MS, Graybill RJ, Larsen RA, Pappas PG, Perfect JR, Powderly WG, Sobel JD, Dismukes WE. Practice guidelines for the management of cryptococcal disease. Infectious Diseases Society of America. Clin Infect Dis 2000; 30: $710-8$.

49. Perfect JR, Dismukes WE, Dromer F, Goldman DL, Graybill JR, Hamill RJ, Harrison TS, Larsen RA, Lortholary O, Nguyen MH, Pappas PG, Powderly WG, Singh N, Sobel JD, Sorrell TC. Clinical practice guidelines for the management of cryptococcal disease: 2010 update by the Infectious Diseases Society of America. Clin Infect Dis 2010; 50: 291-322.

50. Graybill JR, Sobel J, Saag M, van Der Horst C, Powderly W, Cloud G, 
Riser L, Hamill R, Dismukes W. Diagnosis and management of increased intracranial pressure in patients with AIDS and cryptococcal meningitis. The NIAID Mycoses Study Group and AIDS Cooperative Treatment Groups. Clin Infect Dis 2000; 30: 47-54.

51. Shoham S, Cover C, Donegan N, Fulnecky E, Kumar P. Cryptococcus neoformans meningitis at 2 hospitals in Washington, D.C.: adherence of health care providers to published practice guidelines for the management of cryptococcal disease. Clin Infect Dis 2005; 40: 477-9.

52. Zhu LP, Wu JQ, Xu B, Ou XT, Zhang QQ, Weng XH. Cryptococcal meningitis in non-HIV-infected patients in a Chinese tertiary care hospital, 1997-2007. Med Mycol 2010; 48: 570-9.

53. Moretti ML, Resende MR, Lazéra MS, Colombo AL, Shikanai-Yasuda MA. Consenso em criptococose - 2008. Rev Soc Bras Med Trop 2008; 41: 524-44.

54. Liliang PC, Liang CL, Chang WN, Chen HJ, Su TM, Lu K, Lu CH. Shun surgery for hydrocephalus complicating cryptococcal meningitis in human immunodeficiency virus-negative patients. Clin Infect Dis 2003; 3: 673-8.

55. Woodworth GF, McGirt MJ, Williams MA, Rigamonti D. The use of ventriculoperitoneal shunts for uncontrollable intracranial hypertension without ventriculomegally secondary to HIV-associated cryptococcal meningitis. Surg Neurol 2005; 63: 529-31.

56. Calvo A, Hernández P, Spagnuolo E, Johnston E. Surgical treatment of intracranial hypertension in encephalic cryptococcosis. Br J Neurosurg 2003; 17 : $450-5$.

57. Lessells RJ, Mutevedzi PC, Heller T, Newell ML. Poor long-term outcomes for cryptococcal meningitis in rural South Africa. S Afr Med J 2011; 101: 251-2.

58. Bicanic T, Meintjes G, Wood R, Hayes M, Rebe K, Bekker LG, Harrison T. Fungal burden, early fungicidal activity, and outcome in cryptococcal meningitis in antiretroviral-naive or antiretroviral-experienced patients treated with amphotericin B or fluconazole. Clin Infect Dis 2007; 45: 76-80.

59. Bicanic T, Wood R, Meintjes G, Rebe K, Brouwer A, Loyse A, Bekker LG, Jaffar S, Harrison T. High-dose amphotericin B with flucytosine for the treatment of cryptococcal meningitis in HIV-infected patients: a randomized trial. Clin Infect Dis 2008; 47: 123-30.

60. Jarvis JN, Meintjes G, Harrison TS. Outcomes of cryptococcal meningitis in antiretroviral naive and experienced patients in South Africa. J Infect 2010; 60: $496-8$.

61. Bisson GP, Nthobatsong R, Thakur R, Lesetedi G, Vinekar K, Tebas P, Bennett JE, Gluckman S, Gaolathe T, MacGregor RR. The use of HAART is associated with decreased risk of death during initial treatment of cryptococcal meningitis in adults in Botswana. J Acquir Immune Defic Syndr 2008; 49: 227-9.

62. Steele KT, Thakur R, Nthobatsang R, Steenhoff AP, Bisson GP. In-hospital mortality of HIV-infected cryptococcal meningitis patients with $C$. gattii and C. neoformans infection in Gaborone, Botswana. Med Mycol 2010; 48: 1112-5.

63. Kambugu A, Meya DB, Rhein J, O'Brien M, Janoff EN, Ronald AR, Kamya MR, Mayanja-Kizza H, Sande MA, Bohjanen PR, Boulware DR. Outcomes of cryptococcal meningitis in Uganda before and after the availability of highly active antiretroviral therapy. Clin Infect Dis 2008; 46: 1694-701.

64. Makadzange AT, Ndhlovu CE, Takarinda K, Reid M, Kurangwa M, Gona P, Hakim JG. Early vs delayed initiation of antiretroviral therapy for concurrent HIV infection and cryptococcal meningitis in sub-Saharan Africa. Clin Infect Dis 2010; 50: 1532-8.

65. Mwaba P, Mwansa J, Chintu C, Pobee J, Scarborough M, Portsmouth S, Zumla A. Clinical presentation, natural history, and cumulative death rates of 230 adults with primary cryptococcal meningitis in Zambian AIDS patients treated under local conditions. Postgrad Med J 2001; 77: 769-73.

66. Chottanapund S, Singhasivanon P, Kaewkungwal J, Chamroonswasdi K, Manosuthi W. Survival time of HIV-infected patients with cryptococcal meningitis. J Med Assoc Thai 2007; 90: 2104-11.

67. Micol R, Lortholary O, Sar B, Laureillard D, Ngeth C, Dousset J-P, Chanroeun H, Ferradini L, Guerin PJ, Dromer F, Fontanet A. Prevalence, determinants of positivity and clinical utility of cryptococcal antigenemia in Cambodian HIV-infected patients. J Acquir Immune Defic Syndr 2007; 45: 555-9.

68. Espié E, Pinoges L, Balkan S, Chanchhaya N, Molfino L, Narom P, Pujades-
Rodríguez M. Cryptococcal meningitis in HIV-infected patients: a longitudinal study in Cambodia. Trop Med Int Health 2010; 15: 1375-81

69. Lortholary O, Poizat G, Zeller V, Neuville S, Boibieux A, Alvarez M, Dellamonica P, Botterel F, Dromer F, Chêne G. Long-term outcome of AIDSassociated cryptococcosis in the era of combination antiretroviral therapy. AIDS 2006; 20: 2183-91.

70. Leimann BCQ, Koifman RJ. Cryptococcal meningitis in Rio de Janeiro State, Brazil, 1994-2004. Cad Saúde Pública Rio de Janeiro 2008; 24: 2582-92.

71. Moreira Tde A, Ferreira MS, Ribas RM, Borges AS. Criptococose: estudo clínico-epidemiológico, laboratorial e das variedades do fungo em 96 pacientes. Rev Soc Bras Med Trop 2006; 39: 255-8.

72. Severo CB, Xavier MO, Gazzoni AF, Severo LC. Cryptococcosis in children Paediatr Respir Rev 2009; 10: 166-71.

73. Lizarazo J, Restrepo A, Castañeda E y el Grupo Colombiano de estudio de la criptococosis. Supervivencia y secuelas de pacientes registrados por el Grupo Colombiano de Estudio de la Criptococosis (1997-2001). Inf Quinc Epidemiol Nac 2002; 7: 449-53.

74. Diamond RD, Bennett JE. Prognostic factors in cryptococcal meningitis. A study in 111 cases. Ann Intern Med 1974; 80: 176-81.

75. Dismukes WE, Cloud G, Gallis HA, Kerkering TM, Medoff G, Craven PC, Kaplowitz LG, Fisher JF, Gregg CR, Bowles CA, et al. Treatment of cryptococcal meningitis with combination amphotericin B and flucytosine for four as compared with six weeks. N Engl J Med 1987; 317: 334-41.

76. Dromer F, Mathoulin-Pelissier S, Launay O, Lortholary O. Determinants of disease presentation and outcome during cryptococcosis: the Crypto A/D study. PLoS Med 2007; 4: e21

77. Saag MS, Powderly WG, Cloud GA, Robinson P, Grieco MH, Sharkey PK, Thompson SE, Sugar AM, Tuazon CU, Fisher JF, et al. Comparison of amphotericin B with fluconazole in the treatment of acute AIDS-associated cryptococcal meningitis. The NIAID Mycoses Study Group and the AIDS Clinical Trials Group. N Eng J Med 1992; 326: 83-9.

78. Lortholary O, Fontanet A, Mémain N, Martin A, Sitbon K, Dromer F; French Cryptococcosis Study Group. Incidence and risk factors of immune reconstitution inflammatory syndrome complicating HIV-associated cryptococcosis in France. AIDS 2005; 19: 1043-9.

79. Jarvis JN, Meintjes G, Williams Z, Rebe K, Harrison TS. Symptomatic relapse of HIV-associated cryptococcal meningitis in South Africa: the role of inadequate secondary prophylaxis. S Afr Med J 2010; 100: 378-82

80. Lizarazo J, Peña Y, Cháves, Omaña R, Huérfano S, Castañeda E. Diag nóstico temprano de la criptococosis y la histoplasmosis en pacientes que viven con el sida. Informe preliminar. Inf Quinc Epidemiol Nac 2002; 7: 453-8.

81. Liechty CA, Solberg P, Were W, Ekwaru JP, Ransom RL, Weidle PJ, et al. Asymptomatic serum cryptococcal antigenemia and early mortality during antiretroviral therapy in rural Uganda. Tropical Med International Health 2007; 12: $929-35$

82. Lindsley MD, Nanthawan M, Baggett HC, Surinthong Y, Autthateinchai R, Sawatwong P, Harris JR, Park BJ, Chiller T, Balajee SA, Poonwan N. Evaluation of a newly developed lateral flow immunoassay for the diagnosis of cryptococcosis, Clin Infect Dis 2011; 53: 321-5

83. Jarvis JN, Percival A, Bauman S, Pelfrey J, Meintjes G, Williams GN, Longley N, Harrison TS, Kozel TR. Evaluation of a novel point-of-care cryptococcal antigen test on serum, plasma, and urine from patients with HIV-associated cryptococcal meningitis. Clin Infect Dis 2011; 53: 1019-23.

84. Fyfe M, MacDougall L, Romney M, Starr M, Pearce M, Mak S, Mithani S, Kibsey P. Cryptococcus gattii infections on Vancouver Island, British Columbia, Canada: emergence of a tropical fungus in a temperate environment. Can Commun Dis Rep 2008; 34: 1-12.

85. Byrnes EJ 3rd, Li W, Lewit Y, Ma H, Voelz K, Ren P, Carter DA, Chaturvedi V, Bildfell RJ, May RC, Heitman J. Emergence and pathogenicity of highly virulent Cryptococcus gattii genotypes in the northwest United States. PLoS Pathog 2010; 6(4): e1000850. 